\title{
Review
}

Journal of Innate

Immunity
J Innate Immun 2011;3:131-141

DOI: $\underline{10.1159 / 000323963}$
Received: December 8, 2010

Accepted after revision: January 3, 2011

Published online: January 21, 2011

\section{Modifications of the Innate Immune System in Atopic Dermatitis}

\author{
Laura Maintz Natalija Novak \\ Department of Dermatology and Allergy, University of Bonn, Bonn, Germany
}

\section{Key Words \\ Allergy $\cdot$ Antimicrobial peptides $\cdot$ Pathogen-associated molecular patterns $\cdot$ Toll-like receptor}

\begin{abstract}
Atopic dermatitis (AD) is a frequent chronic inflammatory skin disease which is often complicated by recurrent microbial superinfections. Genetically based modifications which might have an impact on the innate immune system, such as impairment of the skin barrier, modifications of pattern recognition receptors, deficiency of antimicrobial peptides, antiviral natural killer cells and plasmacytoid dendritic cells, facilitate the entry of allergens and infectious microbes into the skin, where they encounter immunocompetent cells. The micromilieu in the skin of AD patients further potentiates dysfunctions of the innate immune system, leading to a vicious circle promoting the disease. This article provides an overview of modifications of the innate immune system in AD.

Copyright @ 2011 S. Karger AG, Basel
\end{abstract}

\section{Introduction}

Atopic dermatitis (AD) is a multifactorial chronic inflammatory skin disease characterized by pruritic, typical distributed eczematous skin lesions, disturbed skin barrier and modified innate and adaptive immunity with a proneness to IgE-mediated sensitization, infections and hyperreactivity to environmental influences with a strong genetic predisposition. Current studies revive the question whether the disturbed epidermal barrier in $\mathrm{AD}$ leads to modified innate and adaptive immune responses (inside-outside), or the other way round (outside-inside paradigm).

Innate immunity consists of cellular and biochemical defense mechanisms that provide a rapid response to invasion of microbes after their recognition by pattern recognition receptors (PRR). The principal components of innate immunity are physical and chemical barriers such as epithelia and antimicrobial substances produced at epithelial surfaces, circulating effector cells [neutrophils, macrophages, natural killer (NK) cells], circulating effector proteins such as mannose-binding lectin, and cytokines such as tumor necrosis factor (TNF), interleukins (IL)-1, -12, -18, -23, -15 and -10, chemokines, interferons (IFN) $-\alpha,-\beta$ and $-\gamma$, and transforming growth factor- $\beta$ that regulate and coordinate many of the activities of the cells of innate immunity. Defense against microbes is mediated by the early reactions of innate immunity and the later responses from adaptive immunity. Alterations in both innate and adaptive immunity have been described in $\mathrm{AD}$, leading to frequent bacterial, viral and mycotic superinfections which trigger and aggravate the course of the disease. This article aims to provide an overview of modifications of the innate immune system in AD discovered in recent times.

\section{KARGER}

Fax +4161306 1234

E-Mail karger@karger.ch

www.karger.com (c) 2011 S. Karger AG, Basel

$1662-811 X / 11 / 0032-0131 \$ 38.00 / 0$

Accessible online at:

www.karger.com/jin
Prof. Dr. Natalija Novak

Department of Dermatology and Allergy

University of Bonn

Sigmund-Freud-Strasse 25, DE-53127 Bonn (Germany)

Tel. +49 2282871 5370, E-Mail Natalija.Novak@ukb.uni-bonn.de 


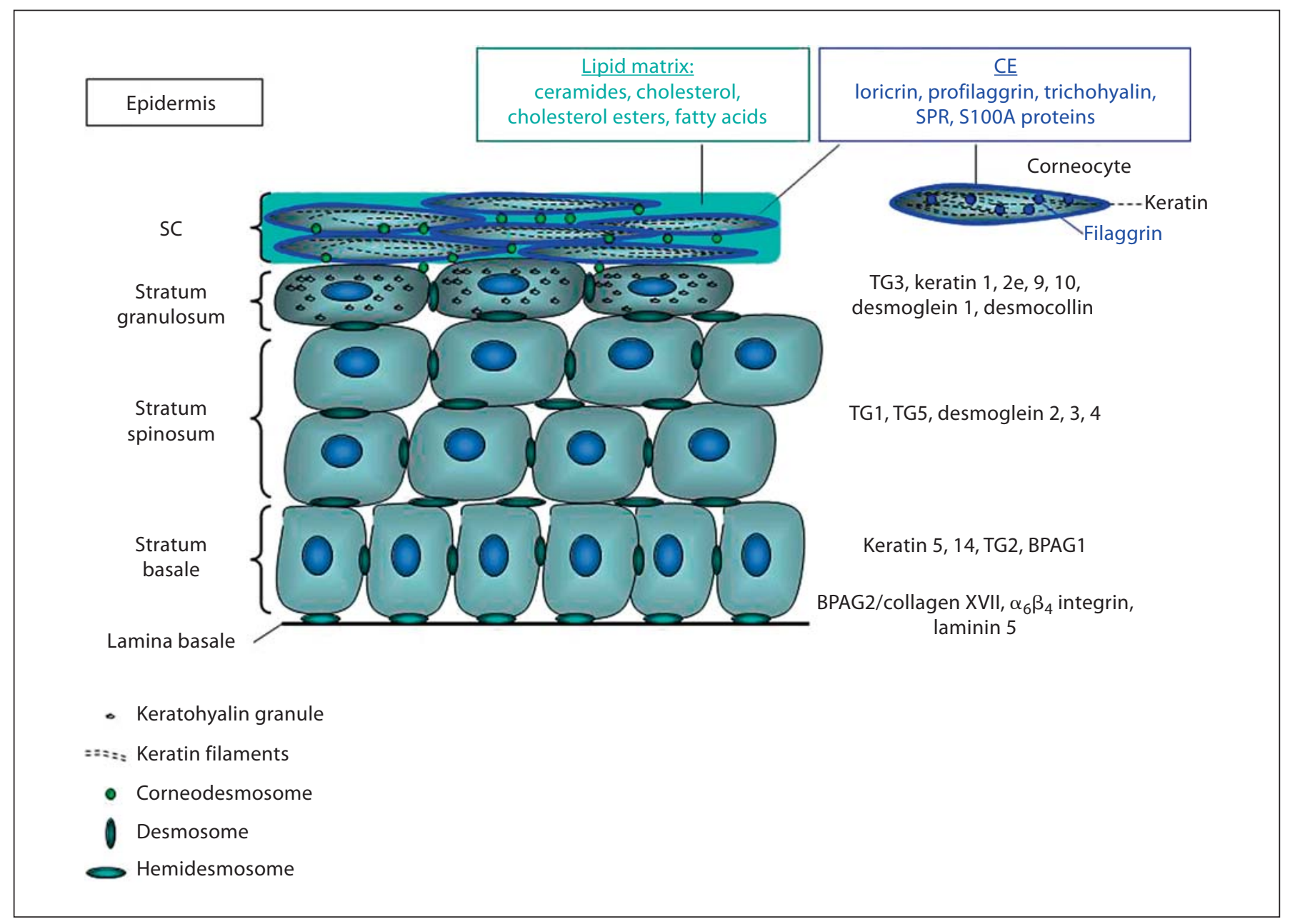

Fig. 1. Diagram of the epidermis. Adapted from Candi et al. [2]. BPAG = Bullous pemphigoid antigen; $\mathrm{CE}=$ cornified envelope; $\mathrm{SC}=$ stratum corneum; $\mathrm{SPR}=$ small proline-rich protein; $\mathrm{TG}=$ transglutaminase.

\section{Genetically Based Skin Barrier Dysfunction in AD}

A modified skin barrier with increased transepidermal water loss and reduced hydration of the skin is a characteristic feature of $\mathrm{AD}$ patients, whereupon the extent of barrier dysfunction correlates with AD severity [1]. The epidermis functions both as a physical barrier and as an active immunological organ. During differentiation, keratinocytes (KC) move from a proliferative cell type in the basal cell layer of the epidermis through the granular layer, where the cornified envelope (CE) is formed, to an association of flattened, dead cell remnants (corneocytes) in the uppermost layer of the skin, the stratum corneum (SC). The CE is an insoluble protein structure that is cross-linked by transglutaminases to replace the plasma membrane in corneocytes, where it functions as a scaffold for lipid attachment. This structure prevents epidermal water loss and also impedes the entry of allergens, irritants and infectious organisms. A matrix of lipids such as ceramides, cholesterol, fatty acids and cholesterol esters compasses the corneocytes and builds the critical barrier to transepidermal water loss. Corneodesmosomes function as adhesion molecules between the corneocytes (fig. 1) [2]. AD patients exhibit a reduced expression of ceramides and CE proteins such as involucrin, loricrin, filaggrin (filament-aggregating protein, FLG) and keratin $\mathrm{K} 5$ and $\mathrm{K} 16$ in both lesional and nonlesional skin [3].

In the last years, FLG has gained outstanding interest due to the strong association of $\mathrm{AD}$ with polymorphisms in the filaggrin gene ( $F L G$; chrlq21, epidermal differen- 
tiation complex), which have been replicated in multiple case-control and family studies, leading to a paradigm shift from a primary immunological disease towards a dysfunction of the epidermal barrier [4].

FLG consolidates the keratin filaments into dense bundles, represents an integral part of the epidermis and is crucial for the development of the $\mathrm{CE}$ to engineer and maintain the barrier function of the uppermost layer of the skin. Moreover, FLG degradation products such as hygroscopic amino acids serve as a natural moisturizing factor, and acidic metabolites of FLG can influence the $\mathrm{pH}$ of the skin and increase serine protease (SP) activity. The FLG mutations 228del 4 and R501X are the main FLG variants in Europeans, with a combined allele frequency of about $6 \%$. Moreover, 18 infrequent variants have been found in populations with European ancestry, and an additional 17 mutations in Asian populations. All variants lead to nonsense mutations and impede or rather decrease the production of free epidermal FLG [4]. FLG null mutations have been described in $16-23 \%$ of all $\mathrm{AD}$ patients in central European studies, and in $22-45 \%$ in studies from the UK. The strongest association with FLG mutations have been observed in AD patients with high total serum IgE, concomitant sensitizations and an early onset of $\mathrm{AD}$ with a chronic, persistent course until adulthood. Combined analysis shows an increased risk of FLG haploinsufficiency for both eczema as well as for the combined phenotype of AD with asthma, but not for asthma without eczema [4]. The effect of FLG on the risk of eczema is considerably higher than the effect of other candidate genes on atopic diseases, and it is one of the strongest effects reported and replicated in the genetics of complex diseases [4].

Besides mutations in the FLG and several genes for atopy and inflammation, AD has also been associated with mutations in other genes for proteins contributing to the skin barrier, such as the SP SC chymotryptic enzyme, kallikrein-related peptidase 7 (KLK7) and the SP inhibitor LEKTI (SPINK5), which contribute to the balance of proteases and antiproteases in the skin, and CLDN1, encoding claudin 1 . The tight junction protein claudin 1 controls the permeability of epithelial cells to water and other soluble components and immune cells and is decreased in patients with $\mathrm{AD}$ [5].

SP are involved in the proteolytic degradation of corneodesmosomes and, together with lipid-processing enzymes such as sphingomyelinases, in the desquamation of the corneocytes from the SC surface. Sustained SP activity by a slight, prolonged alkanization in $\mathrm{pH}$ from 5.0 to 5.5 in $\mathrm{AD}$ patients is suspected to induce abnormalities in both SC integrity, cohesion and permeability barrier homeostasis. SP mediate proinflammatory effects via the proteinase-activated receptor 2 (PAR2), which is highly expressed on $\mathrm{KC}$ and dermal endothelial cells. These cells react to PAR2 signals with hyperproliferation and an increased expression of proinflammatory cytokines and chemokines. Moreover, activation of PAR2 on human skin mast cells induces the release of histamine. Acute barrier disruption increases SP activity and activates PAR2. Tryptase and trypsin-related enzymes act as endogenous PAR2 activators, tryptic enzymes from Staphylococcus aureus and house dust mite (HDM) as exogenous PAR2 activators. Besides the induction of an allergen-specific immune reaction, HDM might thus elicit an additional nonimmunologic inflammatory reaction in both sensitized and nonsensitized individuals.

The partly genetically based skin barrier dysfunction permits an invasion of the skin by antigens, bacteria and viruses, where they encounter immunocompetent epidermal and dermal cells and thus influence the course of the disease. Fitting into this, FLG-deficient mice display an increased uptake of allergens through the skin, leading to an IgE-mediated sensitization and development of an atopic skin inflammation with an overexpression of IL-17, $-6,-23$ and -4 as well as IFN- $\gamma[6]$. However, $40 \%$ of patients with FLG null alleles do not suffer from AD, and null mutations causing the FLG deficiency could only be demonstrated in about $1 / 3$ of the patients. Interestingly, Th2 cytokines have been shown to downregulate the expression of FLG [7], other CE proteins such as loricrin and involucrin [8], and also ceramide synthesis [9]. Thus, a part of the $\mathrm{AD}$ patients seems to acquire the skin barrier dysfunction by atopic inflammatory response, or the genetic predisposition to a dysregulated skin barrier is amplified by the inflammatory micromilieu in $\mathrm{AD}$ [7].

\section{Mutations in Genes for PRR}

Via special PRR, the innate immune system recognizes highly conserved pathogen-associated molecular patterns (PAMP), which are shared by groups of related microbes and which do not occur in humans. This leads to the rapid activation of cellular and biochemical defense mechanisms of the innate immune system and subsequent reactions of the adaptive immune system. Several PRR such as Toll-like receptors (TLR) or intracellular nucleotide-binding oligomerization domains (NOD)/caspase recruitment domains (CARD) distinguish between different PAMP. TLR are expressed by various cells of the 
innate immune system such as macrophages, dendritic cells (DC), neutrophils, mucosal epithelial and endothelial cells. Recognition of their ligands induces a conserved host recognition program via nuclear factor- $\kappa \mathrm{B}$, leading to the expression of proinflammatory cytokines (TNF- $\alpha$, IL-1, IL-12), endothelial adhesion molecules (E-selectin), costimulatory molecules and antimicrobial mechanisms [antimicrobial peptides (AMP), inducible nitric oxide synthase]. Activation of DC by TLR ligands is crucial for their maturation and ability to initiate adaptive immune responses. Weak TLR2 and TLR4 signals in the context of allergen exposure in the skin and lung, respectively, have been shown to promote a Th2-based immune response [5]. TLR2 recognizes fungal zymosan, lipopolysaccharides and other PAMP such as components of the staphylococcal cell wall [lipoteichoic acid (LTA), peptidoglycan (PGN)], and is thus essential for the response to several bacteria, mycobacteria, protozoa and fungi. Associations of the single nucleotide polymorphisms (SNPs) R753Q [10] and A-6934T [11] in the TLR2 gene with severe forms of AD have been described [10], but the association of R753Q could not be replicated in another study [12]. Furthermore, no association of AD could be shown with SNPs in the TLR3 [13], TLR4 [11, 12] or TLR6 gene. There were no significant differences in mRNA expression of TLR 1, 2, 3, 5 and 6 between skin biopsies of patients with $\mathrm{AD}$ and psoriasis [14]. However, lower TLR2 expression was observed on macrophages of patients with $\mathrm{AD}$, and macrophages of patients with $\mathrm{AD}$ produced less proinflammatory cytokines (IL-6, -8, -1ß) after stimulation with PGN and LTA [15]. Heterozygous carriers of TLR2 R753Q with AD displayed a reduced surface expression of TLR2 on CD4+ T cells [16], a modified expression of CD36 upon stimulation and an increased production of IL- 6 and IL- 12 by monocytes after TLR 2 stimulation compared to wild-type $\mathrm{AD}$ patients and healthy controls [15]. Furthermore, an increased secretion of IL-6 in homozygous carriers of TLR2 $-16934 \mathrm{~A}$ with AD has been observed [11], indicating a modified inflammatory response dependent on this TLR2 polymorphism [15]. Furthermore, $\mathrm{AD}$ has been associated with a polymorphism (C-1237T) resulting in higher promoter activity in the gene encoding TLR9, which is crucial for the recognition of unmethylated CpG DNA sequences of bacteria, protozoa and intracellular viral antigens [17].

There was no evidence for an association of $\mathrm{AD}$ with IRAK-M SNPs encoding an IL-1 receptor-associated kinase $M$ which negatively regulates TLR signaling [18]. Intracellular PAMP, particularly PGN, are recognized by the NOD family of proteins. NOD1- and NOD2-express- ing KC produced IL- 6 after stimulation with PGN, and human $\beta$-defensin (hBD) 2 after stimulation with the NOD2-specific ligand muramyl dipeptide. SNPs of CARD4 (encoding NOD1) [19], NALP12 (another member of the NOD-leucine rich repeat-containing protein family) [20] and CARD15/NOD2 [20, 21] have been observed to be associated with $\mathrm{AD}$, whereas variants of CARD15/NOD2 also modified the risk of developing asthma or allergic rhinoconjunctivitis [21, 22].

The circulating PRR mannose-binding lectin (MBL) recognizes mannose-rich glycans of various pathogens including S. aureus, leading to opsonization and complement activation. In children with $\mathrm{AD}$, an association of SNPs in the MBL gene with $\mathrm{AD}$, related to low or deficient levels of MBL, has been observed compared to healthy controls [23]. Thus, genetically determined low or deficient MBL serum levels may contribute to the predisposition to $\mathrm{AD}$, but not to disease severity [23]. However, a previous Japanese study could not show any association of MBL SNPs with AD [24].

\section{Deficiency of Antimicrobial Peptides (AMP) Contributes to Susceptibility to Skin Infections in AD}

Modified mechanisms of the innate immune system with a deficiency of the AMP human cathelicidin LL-37, $\mathrm{hBD} 2$ and $\mathrm{hBD} 3$ contribute to the proneness of $\mathrm{AD}$ patients to skin infections. The cationic AMP interact with anionic components of bacteria, fungi and viruses, leading to a destruction of the microbial membrane and cell lysis. Moreover, AMP induce the production of several cytokines and chemokines which contribute to the recruitment of neutrophils, monocytes, mast cells and $\mathrm{T}$ cells in the skin [25]. LL-37 and hBD2 show synergistic effects in the elimination of $S$. aureus [26]. Low amounts of AMP, apart from the constitutively expressed hBD1, are expressed in healthy skin, but the synthesis of hBD2 and 3 and of LL-37 by KC increases as a reaction to $S$. aureus and proinflammatory cytokines $[14,26]$. Thus, increased amounts of AMP have been found in the skin of patients with chronic inflammatory skin diseases such as psoriasis and contact dermatitis. In contrast, both lesional and nonlesional skin of AD patients [14] features a decreased expression of hBD2 and 3 and of LL-37 compared to the skin of psoriasis patients $[14,25,26]$. Conversely, recent studies could show an induction of the AMP hBD2 and 3 and RNase 7 in $\mathrm{KC}$ from both patients with $\mathrm{AD}$ and with psoriasis [27]. However, the overexpressed cytokines IL- $4,-13$ and -10 downregulate the TNF- $\alpha-$ and IFN- $\gamma$ - 
induced AMP expression in the skin of AD patients [14, $25,26]$. Both mobilization of hBD3 and killing of $S$. aureus are inhibited by IL- 4 and IL-13, and neutralization of these cytokines has been shown to improve these activities [28]. Furthermore, IL-17-producing T cells, in particular Th2/IL-17 cells, have been shown to infiltrate acute $\mathrm{AD}$ reactions in atopy patch tests. IL-17 secretion is enhanced by the S. aureus-derived superantigen SEB. Although both healthy and $\mathrm{AD} \mathrm{KC}$ upregulate $\mathrm{hBD} 2$ in response to IL-17, coexpression of IL-4 and IL-13 partially inhibited these effects. It has been assumed that the ineffective IL-17-dependent upregulation of hBD2 in patients with $\mathrm{AD}$ is due to a partial inhibition by the Th2-dominated microenvironment in acute AD [29].

In addition to the proneness to bacterial infections due to a deficiency of hBD2 and 3, the cathelicidin deficiency in $\mathrm{AD}$ predisposes to the development of severe viral infections such as the eczema vaccinatum and eczema herpeticum (EH) [25]. EH is a disseminated herpes simplex virus 1 or 2 infection with severe systemic illness that occurs in about $10-20 \%$ of patients with AD. Risk factors for $\mathrm{EH}$ are an early onset of $\mathrm{AD}$, severe and untreated $\mathrm{AD}$, head and neck dermatitis, previous herpes simplex infections and $\mathrm{EH}$, an elevated serum $\operatorname{IgE}$ combined with a higher level of specific sensitizations, especially against Malassezia sympodialis [30]. In lesional skin of AD patients with $\mathrm{EH}$, lower amounts of cathelicidin have been observed than in $\mathrm{AD}$ patients without $\mathrm{EH}$, whereas $\operatorname{IgE}$ serum levels correlated inversely with the expression of LL-37 [25]. In both European and Afro-American patients with $\mathrm{AD} \mathrm{EH}$, a 3-fold higher frequency of the R501X FLG mutation has been found than in AD patients without $\mathrm{EH}$, stressing the essential role of the skin barrier in the prevention of infections.

B-cell leukemia (Bcl)-3 acts as a transcriptional modulator of innate immune function in $\mathrm{KC}$ by modulating the expression of hBD3, cathelicidin, IL-8 and IL-5. Bcl-3 is inducible by the Th2 cytokines IL- 4 and IL-13 and overexpressed in lesional skin of AD patients [31]. Silencing of Bcl-3 by small interfering RNA has been shown to reverse the downregulatory effect of IL-4 on hBD3 expression, indicating that $\mathrm{Bcl}-3$ is required for IL-4-mediated suppression of $\mathrm{hBD} 3$. A vitamin $\mathrm{D}$-responsive element has been identified in the promoter region of the human cathelicidin. Stimulation of $\mathrm{KC}$ with vitamin $\mathrm{D}_{3}\left(1,25 \mathrm{D}_{3}\right)$ increased the transcription and activation of cathelicidin. Interestingly, $\mathrm{Bcl}-3$ silencing enhanced $1,25 \mathrm{D}_{3}$-induced cathelicidin expression in $\mathrm{KC}$, suggesting a negative regulatory function in cathelicidin transcription. $1,25 \mathrm{D}_{3}$ suppressed $\mathrm{Bcl}-3$ expression in vitro and in vivo, suggest- ing an autoregulatory role of $1,25 \mathrm{D}_{3}$ in $\mathrm{Bcl}-3$ function [31]. Furthermore, a downregulation of Bcl-3 expression [31] and upregulation of LL-37 in the skin of AD patients [32] could be shown after oral supplementation with vitamin $\mathrm{D}_{3}$ in a small study conducted in adult $\mathrm{AD}$ patients as a promising new therapeutic option for AMP deficiency. However, further larger studies reproducing this effect are required.

Dermcidin (DCD), another antibacterial and antimycotic AMP, is constitutively expressed in human eccrine sweat glands and secreted into sweat. Patients with AD, most notably with a history of bacterial and viral infections, exhibit a significantly reduced amount of DCDrelated peptides [33]. Additionally, the overall reduced amount of sweat in $\mathrm{AD}$ with a reduced secretion of $\operatorname{IgA}$ and an altered electrolytic composition of the sweat has been supposed to contribute to the susceptibility of $\mathrm{AD}$ patients to skin infections [33].

Furthermore, levels of the antimicrobial sphingolipid metabolite sphingosine are also decreased in the SC of $\mathrm{AD}$ patients. The sphingosine deficiency is supposed to result from decreased levels of ceramides as a substrate, and from diminished activities of its metabolic enzyme acid ceramidase, and it favors even further colonization of AD patients by $S$. aureus [34].

\section{Thymic Stromal Lymphopoietin Functions as a Link between Disturbed Skin Barrier and Th2 Polarization in AD}

$\mathrm{KC}$ are not only essential for the innate immune system due to the expression of TLR and production of AMP after exposure to microbes [35], but they also produce cytokines which mediate responses of the innate and adaptive immune system. KC of $\mathrm{AD}$ patients produce increased amounts of proinflammatory cytokines both constitutively as well as in response to several stimuli such as scratch-induced epidermal trauma, microbial infections and allergens. Most notably, the IL-7-like cytokine thymic stromal lymphopoietin (TSLP) is produced in high amounts by $\mathrm{KC}$ in $\mathrm{AD}$, is upregulated by proinflammatory and Th2 cytokines [36] and functions as an important connector between disturbed skin barrier and Th2 polarization in $\mathrm{AD}$. In immature CD11c+ DC, TSLP induces an increased expression of IL-4, -5 and -13 as well as of chemokines such as chemokine ligand (CCL)17 and CCL22, which leads to the recruitment of Th2 lymphocytes via binding of chemokine receptor (CCR) 4. TSLPactivated $\mathrm{CD} 11 \mathrm{c}+\mathrm{DC}$ then induce the expansion and dif- 
ferentiation of naive CD8+ T cells into IL-5- and IL-13producing effector cells which can exert cytotoxic effects via the production of IFN- $\gamma$ in the presence of the CD40 ligand. Furthermore, TSLP has also been shown to activate mast cells and NK T (NKT) cells. Invariant NKT cells have been shown to be increased both among peripheral blood mononuclear cells and in the skin of patients with severe $\mathrm{AD}$ compared to those with mild or moderate AD and healthy controls. Invariant NKT cells have been shown to express the TSLP receptor and can be activated by TSLP to secrete IL-4 and IL-13 [37]. Transgenic mice with a skin-specific overexpression of TSLP develop an $\mathrm{AD}$-like phenotype with eczematous lesions and inflammatory cellular dermal infiltrates, an increase in CD4+ Th2 cells with expression of homing receptors and increased IgE serum levels. Moreover, allergic skin inflammation elicited by epicutaneous immunization of mice with ovalbumin was severely impaired in TSLP receptor $^{-/-}$mice, which exhibited a decreased infiltration of eosinophils and decreased local expression of Th2 cytokines (IL-4, IL-13). Intradermal injection of anti-TSLP has been shown to block the development of allergic skin inflammation after cutaneous antigen challenge of ovalbumin-immunized wild-type mice [38], suggesting an essential role of TSLP in AD.

\section{Chemokines Promote the Recruitment of Leukocytes into the Atopic Skin}

Chemotactic cytokines (chemokines) are produced by $\mathrm{KC}$, endothelial cells, leukocytes, macrophages, mast cells and DC and regulate the migration of T cells, monocytes, immature DC and eosinophils in extravascular tissues towards a chemical gradient with the help of various adhesion molecules. Increased levels of the chemokines CCL1/I-309, CCL2/monocyte chemoattractant protein-1, CCL3/macrophage inflammatory protein (MIP)-1 $\alpha$, CCL4/MIP-1 $\beta$, CCL5/RANTES (regulated on activation, normal $\mathrm{T}$ cell expressed, and secreted), CCL11/eotaxin, CCL13/monocyte chemoattractant protein-4, CCL17/thymus and activation-regulated chemokine, CCL18/pulmonary and activation-regulated chemokine, CCL20/MIP-3 $\alpha$, CCL22/macrophage-derived chemokine, CCL26/eotaxin-3, CCL27/cutaneous T-cellattracting chemokine, CCL28/mucosa-associated epithelial chemokine and $\mathrm{CX}_{3} \mathrm{CL} 1 /$ fractalkine as well as other chemotactic factors such as IL-16 and soluble CD30 have been found in the blood of $\mathrm{AD}$ patients compared to controls [39]. Enhanced CCL5 levels correlate to total serum IgE levels and eosinophilia, whereas the serum levels of CCL11, 13, 26 and 28 [40] correlate directly with disease activity [39]. An increased expression of CCL11 and its receptor CCR3 has been found in lesional AD skin compared to control skin. In sequential skin biopsies of $\mathrm{AD}$ patients undergoing an atopy patch test, an upregulation of the mRNA expression of nearly all chemokines could be shown in response to the allergen exposition. The development of manifest eczema was mostly accompanied by an increased expression of CCL1, 17 and 18 as well as an increase in CCR5+ and CCR6+ inflammatory dendritic epidermal cells in the skin. Also, skin biopsies of chronic $\mathrm{AD}$ lesions feature a higher expression of CCL1, 17, 18 and 20 than do nonlesional AD skin and psoriasis. Thus, a specific contribution of these chemokines to $\mathrm{AD}$ has been supposed, whereas upregulation of many other chemokines has also been found in other chronic inflammatory skin diseases such as psoriasis [41]. The cytokine- and chemokine-mediated attraction of leukocytes induces the release of proinflammatory mediators and effector cytokines such as IL-31 and proteases (tryptase) which, together with stress-induced neuromediators, mediate pruritus [39]. Several studies stress the important role of CCL1, 2, 5, 13 and 20 and CX3CL1 in the recruitment of circulating progenitor cells of DC as well as of CCR3 ligands (CCL5, 11, 13 and $26)$ to eosinophils in atopic skin [39]. An induction of CCL18 and CCL1/CCR8 could be shown in vivo and in vitro by trigger factors of $\mathrm{AD}$ such as exposition to allergens and microbial antigens such as staphylococcal superantigens or M. sympodialis. Particularly CCL18, the skin-associated CCL27 and its receptor CCR10 appear to play a crucial role in the migration of $\mathrm{T}$ cells in inflammatory skin, the so-called $\mathrm{T}$ cell homing of activated $\mathrm{CD} 4+$ and cutaneous $\mathrm{T}$ cell antigen (CLA)-positive $\mathrm{T}$ cells [39]. As a result of continuous activation of epidermal cytokines due to the skin barrier dysfunction, already minimal exogenous skin trauma or exposure to other provocation factors such as microbial antigens or allergens suffice to amplify cytokine and chemokine production and to reactivate the disease in as yet clinically unaffected skin in AD patients [42].

\section{S. aureus Aggravates AD by both Specific and Unspecific Mechanisms}

$\mathrm{AD}$ is frequently complicated by recurrent skin infections with bacterial, viral and mycotic pathogens. Most notably, S. aureus with its cell wall components LTA and 
Table 1. Modified innate immune system in AD

\begin{tabular}{|c|c|c|}
\hline Components & Main function & Findings in AD \\
\hline Skin barrier & $\begin{array}{ll}\text { - } & \text { physical barrier } \\
\text { - } & \text { prevents the entry of allergens, microbes and irritants } \\
\text { into the skin } \\
\text { - } & \text { active immunological organ }\end{array}$ & $\begin{array}{ll}- & \uparrow \text { transepidermal water loss } \\
- & \quad \downarrow \text { hydration of the skin } \\
\text { - } \quad \downarrow \text { lipid content }\end{array}$ \\
\hline $\mathrm{CE}$ & $\begin{array}{l}\text { - } \quad \text { prevents epidermal water loss } \\
\text { - } \quad \text { impedes the entry of allergens, irritants and infectious } \\
\text { organisms } \\
\text { - } \quad \begin{array}{l}\text { FLG degradation products such as hygroscopic amino } \\
\text { acids serve as a natural moisturizing factor }\end{array} \\
\text { - acidic metabolites of FLG influence the pH of the skin } \\
\text { and serine protease activity }\end{array}$ & $\begin{array}{l}\text { - } \quad \downarrow \text { expression of CE proteins: involucrin, loricrin, FLG, keratin K5 } \\
\text { and K16 } \\
\text { - } \quad \text { FLG null mutations } \rightarrow \downarrow \text { production of FLG } \\
\text { - } \quad \text { FLG null mutations found in } 16-23 \% \text { of all AD patients (Central } \\
\text { Europe), and in } 22-45 \% \text { (UK) increase the risk for eczema and } \\
\text { AD with concomitant asthma } \\
\text { - Th2 cytokines (IL-4 and IL-13) downregulate the expression of } \\
\text { CE proteins FLG, loricrin and involucrin }\end{array}$ \\
\hline Claudin 1 & $\begin{array}{l}\text { - tight junction protein controlling the epidermal } \\
\text { permeability to water and other soluble components } \\
\text { and immune cells }\end{array}$ & $\begin{array}{ll}- & \text { CLDN1-mutations } \\
- & \downarrow \text { claudin } 1 \text { expression }\end{array}$ \\
\hline Ceramides & $\begin{array}{l}\text { - lipid matrix as a critical barrier to transepidermal } \\
\text { water loss }\end{array}$ & $\begin{array}{ll}\text { - } & \downarrow \text { expression of ceramides in the skin } \\
- & \downarrow \text { activity of acid sphingomyelinase-generating ceramides } \\
\text { - } & \uparrow \text { secretion of ceramidase by S. aureus }\end{array}$ \\
\hline $\mathrm{KC}$ & $\begin{array}{l}\text { - epidermal cells/compound of the physical skin barrier } \\
\text { - } \quad \text { cytokine production }\end{array}$ & $\begin{array}{l}\text { - } \quad \begin{array}{l}\text { production of TSLP and other proinflammatory cytokines and } \\
\text { chemokines constitutively and in response to several stimuli } \\
\text { (scratch-induced epidermal trauma, microbial infections and }\end{array} \\
\text { allergens) } \\
\rightarrow \quad \text { recruitment of Th2 cells, DC, eosinophils to the skin }\end{array}$ \\
\hline NOD & - $\quad$ recognition of intracellular PAMP & 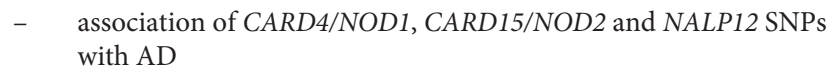 \\
\hline MBL & - $\quad$ recognition of mannose-rich glycans, soluble PRR & $\begin{array}{l}\text { - association of } M B L \text { SNPs with AD in children, but not with AD } \\
\text { severity }\end{array}$ \\
\hline AMP & - $\quad$ microbial killing & \\
\hline AMP & - $\quad$ microbial killing & $\begin{array}{ll}- & \downarrow \text { expression of cathelicidin LL-37, } \mathrm{hBD} 2 \text { and } \mathrm{hBD} 3 \\
- & \text { downregulation of AMP by the overexpressed cytokines IL-4, -13 } \\
\text { and -10 } & \text { negative correlation of IgE levels with LL-37 expression } \\
- & \begin{array}{l}\text { ineffective IL-17-dependent upregulation of hBD2 in AD due to } \\
\text { a partial inhibition by the type } 2 \text { microenvironment }\end{array}\end{array}$ \\
\hline DCD & - $\quad$ antibacterial and antimycotic AMP & - $\quad \downarrow$ amount of DCD-related peptides \\
\hline $\operatorname{IgA}$ & - $\quad$ mucosal immunity & - $\quad \downarrow$ amount of sweat in AD with $\downarrow$ IgA secretion \\
\hline
\end{tabular}


Table 1 (continued)

\begin{tabular}{|c|c|c|}
\hline Components & Main function & Findings in $\mathrm{AD}$ \\
\hline Bcl-3 & - $\quad$ modulation of hBD3 and LL-37 expression in KC & 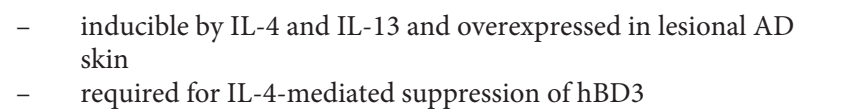 \\
\hline Sphingosine & - $\quad$ antimicrobial sphingolipid metabolite & $\begin{array}{ll}\text { - } & \downarrow \text { sphingosine levels due to } \downarrow \text { ceramide levels as a substrate; } \\
& \downarrow \text { activities of its metabolic enzyme, acid ceramidase }\end{array}$ \\
\hline NK cells & 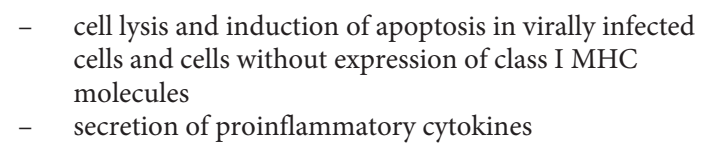 & $\begin{array}{l}\text { - } \quad \text { preferential apoptosis of NK cells and } \gamma \delta+\text { T cells in AD after } \\
\text { contact with activated monocytes } \\
\rightarrow \quad \downarrow \text { circulating NK cells with a } \downarrow \text { TNF- } \alpha \text { and IFN- } \gamma \text { production }\end{array}$ \\
\hline $\mathrm{pDC}$ & $\begin{array}{ll}- & \text { production of antiviral IFN- } \alpha,-\beta \\
- & \text { antigen-presenting cells }\end{array}$ & $\begin{array}{ll}- & \uparrow \text { number of } \mathrm{pDC} \text { in peripheral blood } \\
- & \downarrow \text { number of } \mathrm{pDC} \text { in lesional AD skin } \\
- & \downarrow \text { production of type I IFN after FceRI preactivation }\end{array}$ \\
\hline \multicolumn{3}{|c|}{$\begin{array}{l}\text { AMP = Antimicrobial peptides; } \mathrm{Bcl}-3=\mathrm{B} \text {-cell leukemia } \mathrm{CE}=\text { cornified envelope; } \mathrm{DCD}=\text { demacidin; } \mathrm{FLG}=\text { filaggrin; } \mathrm{IFN}=\mathrm{interferon} ; \mathrm{IL}=\mathrm{inter}- \\
\text { leukin; } \mathrm{KC}=\text { keratinocytes; } \mathrm{MBL}=\text { mannose-binding lectin; } \mathrm{NK} \text { cells = natural killer cells; } \mathrm{NOD}=\text { nucleotide-binding oligomerization domain; } \\
\mathrm{PAMP}=\text { pathogen-associated molecular pattern; } \mathrm{PDC}=\text { plasmacytoid dendritic cells; } \mathrm{PMN}=\text { polymorphonuclear leukocyte; } \mathrm{PRR}=\text { pattern recognition } \\
\text { receptor; SNPs = single nucleotide polymorphisms; } \mathrm{SP}=\text { serine protease; } \mathrm{TLR}=\text { Toll-like receptor; } \mathrm{TSLP}=\text { thymic stromal lymphopoietin. }\end{array}$} \\
\hline
\end{tabular}

PGN is a current provocation factor for exacerbation of AD. A colonization by $S$. aureus of $>90 \%$ could be shown in lesional, and of $76 \%$ in nonlesional skin of $\mathrm{AD}$ patients, while healthy skin has $5-30 \%$ S. aureus colonization. The increased secretion of ceramidase by $S$. aureus results in ceramide deficiency and, thus, contributes to the disturbed skin barrier in AD. An increased affinity and binding of $S$. aureus has partly been ascribed to the modified composition of fibrin and fibrinogen in $\mathrm{AD}$ [43]. S. aureus PGN stimulates the production of granulocyte macrophage colony-stimulating factor and CCL5 by KC [44], and thus adds to the recruitment of leukocytes and inflammation in AD. About $50-60 \%$ of the $S$. aureus strains found in $\mathrm{AD}$ produce enterotoxins such as $S$. aureus enterotoxin A (SEA), B (SEB), C (SEC), D (SED), etc., to which a part of the patients are sensitized. Moreover, enterotoxins can function as superantigens with antigen-independent $T$ cell proliferation via direct interaction with the major histocompatibility complex (MHC) II complex and $\beta$-chain of the T cell receptor. Application of $S$. aureus or its enterotoxins has been shown to induce an eczematous inflammation. They lead to the recruitment of skin-homing CLA+ memory $\mathrm{T}$ cells and Langerhans cells in the atopic skin via the induction of CCL1 and CCL18 production in DC, KC and endothelial cells [39]. SEB has been shown to enhance HDM-induced patch test reactions in patients with AD [45]. An induction of the pruritogenic cytokine IL-31 by staphylococcal superantigens could be shown both in vitro and in vivo. Superantigens have been assumed to suppress the suppressive functions of $\mathrm{T}_{\text {reg }}$ and to induce a resistance to corticosteroids via the production of glucocorticoid receptor- $\beta$ [46]. The impact of these characteristics of $S$. aureus is clinically mirrored by the correlation of disease severity to colonization of eczematous lesions by $S$. aureus and to the amount of specific IgE levels of $S$. aureus enterotoxin. Moreover, $S$. aureus $\alpha$-toxin has been shown to induce a Th1 response resulting in the proliferation of CD4+, INF- $\gamma$-producing T cells [47]. Furthermore, S. aureus has been shown to produce aureolysin, a metalloproteinase which cleaves and inactivates LL-37. Various S. aureus strains have been shown to express the mprF gene conferring resistance to defensins by modifying the charge on bacterial membranes [5]. Thus, S. aureus can promote its own survival by interfering with the AMP that are reduced anyway in AD. 
Preferential Apoptosis of NK Cells and $\gamma \delta+\mathrm{T}$ Cells, a Decreased Amount of IFN- $\alpha$ - and IFN- $\beta$-Producing Plasmacytoid DC and Impaired Recruitment of Polymorphonuclear Leukocytes Facilitate Infections in AD

NKT cells and type I IFN mediate the early innate immune response to viral infections. NK cells kill infected cells and cells that have lost expression of class I MHC molecules. NK cells have granules containing perforin, which creates pores in target cell membranes and granzymes which enter through target cell membranes and induce apoptosis of target cells, mainly cells infected with viruses and intracellular bacteria. NK cells also secrete IFN- $\gamma$, which activates macrophages to phagocyte and to kill microbes and secrete cytokines that stimulate inflammation.

$\mathrm{AD}$ patients have been shown to display profoundly reduced amounts of circulating NK cells and $\gamma \delta+$ T cells with a defective ability to sustain TNF- $\alpha$ and IFN- $\gamma$ production after in vitro stimulation. Furthermore, apoptosis was preferentially observed in NK and $\gamma \delta+\mathrm{T}$ cells from AD patients when stimulated in the presence of monocytes, and depletion of monocytes significantly protected these cells from apoptosis. It has been assumed that once NK and $\gamma \delta+$ T cells in AD patients are in immediate contact with activated monocytes, these cells are specifically targeted for apoptosis, leading to reduced type 1 cytokine production, thereby directing subsequent acquired immune responses toward a type 2 pattern and increasing susceptibility to infection [48].

Activated plasmacytoid DC (pDC) can produce the antiviral type I IFN- $\alpha$ and $-\beta$, which inhibit viral replication and enhance the recognition of MHC I-associated viral antigens on infected cells and, therefore, the efficiency of cytolytic T lymphocyte-mediated killing of these cells. pDC have been shown to express FceRI, whereas the amount of FceRI-bound IgE depends on disease activity and IgE serum levels [49]. Thus, pDC are able to process allergens via FceRI-IgE and promote Th2 responses in vitro. While the number of pDC is increased in peripheral blood of $\mathrm{AD}$ patients, only a small number of $\mathrm{pDC}$ have been found in lesional epidermal skin of $\mathrm{AD}$ patients [50]. Aggregation of FceRI on pDC induces the release of IL-10, and it could be shown in vitro that IL-10 as well as the overexpressed IL-4 induce apoptosis in a negative feedback loop [51]. Therefore, the influence of the Th2 micromilieu of the skin as well as a decreased expression of skin-homing molecules such as CLA and $\mathrm{L}$-selectin CD62L in peripheral blood of AD patients have been assumed to cause the low amount of $\mathrm{pDC}$ in atopic skin [51]. FceRI-preactivated pDC producelower amounts of type I IFN after stimulation with viral DNA and bacterial CpG [51], which together with the deficiency of AMP may contribute to the increased susceptibility of AD patients to infections.

Furthermore, an impaired recruitment of polymorphonuclear leukocytes (PMN) to lesional AD skin has been reported, which has been attributed to a decreased CD11b upregulation after activation by CXCL8/IL-8 and CXCL1/GROa and priming (granulocyte macrophage colony-stimulating factor) stimuli as well as to a reduced production of PMN chemoattractants such as CXCL8/IL-8 and LL-37 in AD. Moreover, functional alterations in $\mathrm{AD} P M N$ with an impaired release of $\beta$ glucuronidase, leukotriene $\mathrm{B}_{4}$, absent deposition of extracellular PMN granule proteins (lactoferrin and PMN elastase) in the skin, impaired phagocytosis and a reduced capacity to produce reactive oxygen species have been observed [5].

\section{Conclusions}

$\mathrm{AD}$ is often complicated by recurrent bacterial, viral and mycotic superinfections. Partly genetically based modifications of the innate immune system such as a disturbed skin barrier, modifications of PRR, deficiency of AMP, antiviral NK cells and pDC facilitate the entry of infectious microbes into the skin where they encounter immunocompetent cells. The Th2-driven micromilieu in the skin of AD patients further potentiates the dysfunction of the innate immune system, leading to a vicious circle promoting the disease (table 1.)

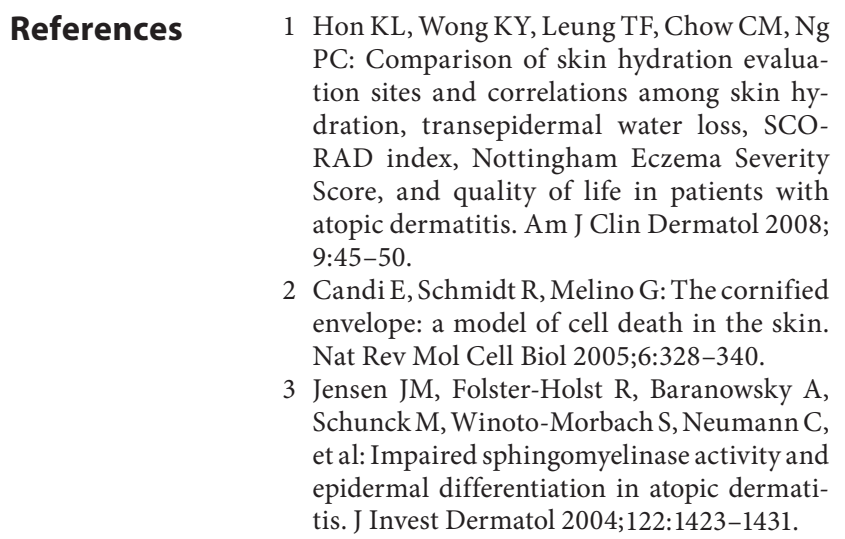

J Innate Immun 2011;3:131-141 139 
4 Rodriguez E, Baurecht $\mathrm{H}$, Herberich E, Wagenpfeil S, Brown SJ, Cordell HJ, et al: Metaanalysis of filaggrin polymorphisms in eczema and asthma: robust risk factors in atopic disease. J Allergy Clin Immunol 2009;123: 1361-1370.

5 de Benedetto A, Agnihothri R, McGirt LY, Bankova LG, Beck LA: Atopic dermatitis: a disease caused by innate immune defects? J Invest Dermatol 2009;129:14-30.

-6 Oyoshi MK, Murphy GF, Geha RS: Filaggrin-deficient mice exhibit TH17-dominated skin inflammation and permissiveness to epicutaneous sensitization with protein antigen. J Allergy Clin Immunol 2009;124: 485-493, 493e1.

7 Howell MD, Kim BE, Gao P, Grant AV, Boguniewicz M, de Benedetto A, et al: Cytokine modulation of atopic dermatitis filaggrin skin expression. J Allergy Clin Immunol 2007;120:150-155.

$\checkmark 8$ Kim BE, Leung DY, Boguniewicz M, Howell $\mathrm{MD}$ : Loricrin and involucrin expression is down-regulated by Th2 cytokines through STAT-6. Clin Immunol 2008;126:332-337.

-9 Hatano Y, Terashi H, Arakawa S, Katagiri K: Interleukin-4 suppresses the enhancement of ceramide synthesis and cutaneous permeability barrier functions induced by tumor necrosis factor-alpha and interferon-gamma in human epidermis. J Invest Dermatol 2005 124:786-792.

10 Ahmad-Nejad P, Mrabet-Dahbi S, Breuer K, Klotz M, Werfel T, Herz U, et al: The Toll-like receptor 2 R753Q polymorphism defines a subgroup of patients with atopic dermatitis having severe phenotype. J Allergy Clin Immunol 2004;113:565-567.

-11 Oh DY, Schumann RR, Hamann L, Neumann K, Worm M, Heine G: Association of the Toll-like receptor $2 \mathrm{~A}-16934 \mathrm{~T}$ promoter polymorphism with severe atopic dermatitis. Allergy 2009;64:1608-1615.

-12 Weidinger S, Novak N, Klopp N, Baurecht H, Wagenpfeil S, Rümmler L, et al: Lack of association between Toll-like receptor 2 and Toll-like receptor 4 polymorphisms and atopic eczema. J Allergy Clin Immunol 2006; 118:277-279.

-13 Terhorst D, Kalali BN, Weidinger S, Illig T, Novak N, Ring J, et al: Monocyte-derived dendritic cells from highly atopic individuals are not impaired in their pro-inflammatory response to Toll-like receptor ligands. Clin Exp Allergy 2007;37:381-390.

$\checkmark 14$ Nomura I, Goleva E, Howell MD, Hamid QA, Ong PY, Hall CF, et al: Cytokine milieu of atopic dermatitis, as compared to psoriasis, skin prevents induction of innate immune response genes. J Immunol 2003;171: 3262-3269.

15 Niebuhr M, Lutat C, Sigel S, Werfel T: Impaired TLR-2 expression and TLR-2-mediated cytokine secretion in macrophages from patients with atopic dermatitis. Allergy 2009;64:1580-1587.
16 Mrabet-Dahbi S, Dalpke AH, Niebuhr M, Frey M, Draing C, Brand S, et al: The Tolllike receptor $2 \mathrm{R} 753 \mathrm{Q}$ mutation modifies cytokine production and Toll-like receptor expression in atopic dermatitis. J Allergy Clin Immunol 2008;121:1013-1019.

17 Novak N, Yu CF, Bussmann C, Maintz L, Peng WM, Hart J, et al: Putative association of a TLR9 promoter polymorphism with atopic eczema. Allergy 2007;62:766-772.

18 Beygo J, Parwez Q, Petrasch-Parwez E, Epplen JT, Hoffjan S: No evidence of an association between polymorphisms in the IRAK-M gene and atopic dermatitis in a German cohort. Mol Cell Probes 2009;23:16-19.

19 Weidinger S, Klopp N, Rümmler L, Wagenpfeil S, Novak N, Baurecht HJ, et al: Association of NOD1 polymorphisms with atopic eczema and related phenotypes. J Allergy Clin Immunol 2005;116:177-184.

20 Macaluso F, Nothnagel M, Parwez Q, Petrasch-Parwez E, Bechara FG, Epplen JT, et al: Polymorphisms in NACHT-LRR (NLR) genes in atopic dermatitis. Exp Dermatol 2007;16:692-698.

21 Kabesch M, Peters W, Carr D, Leupold W, Weiland SK, von Mutius E: Association between polymorphisms in caspase recruitment domain containing protein 15 and allergy in two German populations. J Allergy Clin Immunol 2003;111:813-817.

22 Weidinger S, Klopp N, Rümmler L, Wagenpfeil S, Baurecht HJ, Gauger A, et al: Association of CARD15 polymorphisms with atopy-related traits in a population-based cohort of Caucasian adults. Clin Exp Allergy 2005;35:866-872.

-23 Carrera MC, Moura P, Crovella S, de Souza PR, de Alencar LC, Sarinho E: High polymorphism of the $M B L 2$ gene in patients with atopic dermatitis. Ann Allergy Asthma Immunol 2010;105:39-42.

24 Hashimoto S, Nakamura K, Oyama N, Kaneko F, Fujita T, Tsunemi Y, et al: Mannose-binding lectin (MBL) single nucleotide polymorphism is not associated with atopic dermatitis in Japanese patients. J Dermatol 2005;32:1038-1040.

25 Howell MD: The role of human beta defensins and cathelicidins in atopic dermatitis. Curr Opin Allergy Clin Immunol 2007; 413-417.

26 Ong PY, Ohtake T, Brandt C, Strickland I, Boguniewicz M, Ganz T, et al: Endogenous antimicrobial peptides and skin infections in atopic dermatitis. N Engl J Med 2002;347: 1151-1160.

27 Harder J, Dressel S, Wittersheim M, Cordes J, Meyer-Hoffert U, Mrowietz U, et al: Enhanced expression and secretion of antimicrobial peptides in atopic dermatitis and after superficial skin injury. J Invest Dermatol 2010;130:1355-1364.
28 Kisich KO, Carspecken CW, Fieve S, Boguniewicz M, Leung DY: Defective killing of Staphylococcus aureus in atopic dermatitis is associated with reduced mobilization of human beta-defensin-3. J Allergy Clin Immunol 2008; 122:62-68.

29 Eyerich K, Pennino D, Scarponi C, Foerster $S$, Nasorri F, Behrendt H, et al: IL-17 in atopic eczema: linking allergen-specific adaptive and microbial-triggered innate immune response. J Allergy Clin Immunol 2009;123: 59-66.

30 Peng WM, Jenneck C, Bussmann C, Bogdanow M, Hart J, Leung DY, et al: Risk factors of atopic dermatitis patients for eczema herpeticum. J Invest Dermatol 2007;127:12611263.

-31 Buchau AS, MacLeod DT, Morizane S, Kotol PF, Hata T, Gallo RL: Bcl-3 acts as an innate immune modulator by controlling antimicrobial responses in keratinocytes. J Invest Dermatol 2009;129:2148-2155.

- 32 Hata TR, Kotol P, Jackson M, Nguyen M, Paik A, Udall D, et al: Administration of oral vitamin $\mathrm{D}$ induces cathelicidin production in atopic individuals. J Allergy Clin Immunol 2008;122:829-831.

33 Rieg S, Steffen H, Seeber S, Humeny A, Kalbacher H, Dietz K, et al: Deficiency of dermcidin-derived antimicrobial peptides in sweat of patients with atopic dermatitis correlates with an impaired innate defense of human skin in vivo. J Immunol 2005; 174 : 8003-8010.

34 Arikawa J, Ishibashi M, Kawashima M, Takagi Y, Ichikawa Y, Imokawa G: Decreased levels of sphingosine, a natural antimicrobial agent, may be associated with vulnerability of the stratum corneum from patients with atopic dermatitis to colonization by Staphylococcus aureus. J Invest Dermatol 2002;119: 433-439.

35 Sayama K, Komatsuzawa H, Yamasaki K, Shirakata Y, Hanakawa Y, Ouhara K, et al: New mechanisms of skin innate immunity: ASK1-mediated keratinocyte differentiation regulates the expression of beta-defensins, LL37, and TLR2. Eur J Immunol 2005;35: 1886-1895.

36 Bogiatzi SI, Fernandez I, Bichet JC, MarloieProvost MA, Volpe E, Sastre X, et al: Cutting edge: proinflammatory and Th2 cytokines synergize to induce thymic stromal lymphopoietin production by human skin keratinocytes. J Immunol 2007;178:3373-3377.

37 Wu WH, Park CO, Oh SH, Kim HJ, Kwon YS, Bae BG, et al: Thymic stromal lymphopoietin-activated invariant natural killer T cells trigger an innate allergic immune response in atopic dermatitis. J Allergy Clin Immunol 2010;126:290-299, 299e1-4.

38 He R, Oyoshi MK, Garibyan L, Kumar L, Ziegler SF, Geha RS: TSLP acts on infiltrating effector T cells to drive allergic skin inflammation. Proc Natl Acad Sci USA 2008; 105:11875-11880. 
39 Homey B, Steinhoff M, Ruzicka T, Leung DY: Cytokines and chemokines orchestrate atopic skin inflammation. J Allergy Clin Immunol 2006;118:178-189.

40 Ezzat MH, Sallam MA, Shaheen KY: Serum mucosa-associated epithelial chemokine (MEC/CCL28) in atopic dermatitis: a specific marker for severity. Int J Dermatol 2009; 48:822-829.

41 Gros E, Bussmann C, Bieber T, Förster I, Novak N: Expression of chemokines and chemokine receptors in lesional and nonlesional upper skin of patients with atopic dermatitis. J Allergy Clin Immunol 2009;124:753$760 \mathrm{e} 1$.

-42 Strid J, Strobel S: Skin barrier dysfunction and systemic sensitization to allergens through the skin. Curr Drug Targets Inflamm Allergy 2005;4:531-541.

-43 Cho SH, Strickland I, Boguniewicz M, Leung DY: Fibronectin and fibrinogen contribute to the enhanced binding of Staphylococcus aureus to atopic skin. J Allergy Clin Immunol 2001;108:269-274.
44 Matsubara M, Harada D, Manabe H, Hasegawa K: Staphylococcus aureus peptidoglycan stimulates granulocyte macrophage colonystimulating factor production from human epidermal keratinocytes via mitogen-activated protein kinases. FEBS Lett 2004;566: 195-200.

45 Langer K, Breuer K, Kapp A, Werfel T: Staphylococcus aureus-derived enterotoxins enhance house dust mite-induced patch test reactions in atopic dermatitis. Exp Dermatol 2007;16:124-129.

46 Bieber T: Atopic dermatitis. N Engl J Med 2008;358:1483-1494.

-47 Breuer K, Wittmann M, Kempe K, Kapp A, Mai U, Dittrich-Breiholz O, et al: Alpha-Toxin is produced by skin-colonizing Staphylococcus aureus and induces a T helper type 1 response in atopic dermatitis. Clin Exp Allergy 2005;35:1088-1095.
48 Katsuta M, Takigawa Y, Kimishima M, Inaoka M, Takahashi R, Shiohara T: NK cells and gamma delta+ $T$ cells are phenotypically and functionally defective due to preferential apoptosis in patients with atopic dermatitis. J Immunol 2006;176:7736-7744.

49 Novak N, Allam JP, Hagemann T, Jenneck C, Laffer S, Valenta R, et al: Characterization of FceRI-bearing CD123 blood dendritic cell antigen-2 plasmacytoid dendritic cells in atopic dermatitis. J Allergy Clin Immunol 2004;114:364-370.

50 Wollenberg A, Wagner M, Gunther S, Towarowski A, Tuma E, Moderer M, et al: Plasmacytoid dendritic cells: a new cutaneous dendritic cell subset with distinct role in inflammatory skin diseases. J Invest Dermatol 2002;119:1096-1102.

51 Novak N: New insights into the mechanism and management of allergic diseases: atopic dermatitis. Allergy 2009;64:265-275. 